\title{
Wing shape heritability and morphological divergence of the sibling species Drosophila mercatorum and Drosophila paranaensis
}

\author{
EM Moraes ${ }^{1}$, MH Manfrin², AC Laus², RS Rosada ${ }^{2}$, SC Bomfin ${ }^{2}$ and FM Sene ${ }^{1}$ \\ ${ }^{1}$ Departamento de Genética, FMRP, Universidade de São Paulo, Ribeirão Preto-SP 14049-900, Brazil; '2Departamento de Biologia, \\ FFCLRP, Universidade de São Paulo, Ribeirão Preto-SP, Brazil
}

\begin{abstract}
The fruit-flies Drosophila paranaensis and Drosophila mercatorum pararepleta are sibling species belonging to the repleta group. Females of these two species are normally considered to be morphologically indistinguishable while males only differ consistently in the morphology of their genitalia. These species are sympatric throughout a large area of their geographic distribution. In this study, we investigated the degree of morphological divergence between $D$. paranaensis and $D$. mercatorum pararepleta based on morphometric analysis of their wings. The ellipse method was used to describe the placement of the longitudinal and transversal wing veins as well as the size of the wing and the shape of its outline. The heritability under laboratory and field conditions was also estimated from the parameters generated. Multivariate analysis showed that
\end{abstract}

wing morphology possessed sufficient differences to discriminate between the two species with a successful classification rate of $95-98 \%$ for females and $82-87 \%$ for males. The results of the autoclassification were confirmed by a cross-validation test for females (92-96\%). Most measurements possessed significant natural heritability (a mean of 0.48 for $D$. mercatorum and 0.88 for $D$. paranaensis), indicating that the variation observed was related to differences in genes acting additively. The principal difference between the two species was in the placement of the posterior transverse wing vein. However, the pattern of morphological variation in the wings of both species was similar, possibly because of shared restrictions in wing development pathways.

Heredity (2004) 92, 466-473. doi:10.1038/sj.hdy.6800442

Keywords: $D$. mercatorum; $D$. paranaensis; heritability; sibling species; wing morphology; ellipse method

\section{Introduction}

The morphometric analysis of insect wings, principally in the Diptera, has been used to define relationships between closely related taxa (Brown and Shipp, 1978; Rohlf and Archie, 1984). In Drosophila, wing morphology has been used extensively in taxonomic studies and has revealed marked interspecific divergence (Shorrocks, 1972), with intraspecific variation in the wing size and shape also being frequently demonstrated (Hass and Tolley, 1998; Gilchrist et al, 2000; Hoffmann and Shirriffs, 2002).

Despite their structural simplicity, fly wings are an excellent system for studying morphological variation, because the intersections of the wing veins provide many well-defined landmarks suitable for morphometrics (Klingenberg, 2002). Wing shape has been used to assess the quantitative variation in natural populations of Drosophila (Pezzoli et al, 1997; Bitner-Mathé and Klaczko, 1999a; Gilchrist et al, 2000; Hoffmann and Shirriffs, 2002) with some studies suggesting a potential adaptive nature of this trait, based on responses to laboratory conditions or on clinal patterns in wing shape (Imasheva et al, 1995;

Correspondence: FM Sene, Departamento de Genética, FMRP, Universidade de São Paulo, Ribeirão Preto, São Paulo 14049-900, Brazil.

E-mail: famesene@usp.br

Received 14 August 2002; accepted 28 January 2004
Azevedo et al, 1998; Gilchrist et al, 2000; Gilchrist and Partridge, 2001; Hoffmann and Shirriffs, 2002).

Two sibling species belonging to the repleta group of fruit-flies, Drosophila mercatorum and Drosophila paranaensis, have been described based on chromosome structure and reproductive isolation (Patterson and Wheeler, 1942; Barros, 1950). The females of these species are normally considered to be morphologically indistinguishable and the males are distinguishable only by their genitalia (Vilela, 1983). D. mercatorum is divided into subspecies $D$. mercatorum mercatorum and D. mercatorum pararepleta, the latter having a range limited to the eastern side of the Andes (Carson, 1965; Sene, 1986) whereas D. paranaensis is distributed from Mexico to Argentina. These two species are sympatric throughout a large part of their range (Vilela, 1983). Whereas the other species of the repleta group are associated with cacti, D. mercatorum pararepleta and $D$. paranaensis are generalists that occur in diverse environments (Pereira et al, 1983; Vilela et al, 1983).

The aim of this study was evaluate the degree of divergence in wing shape between D. mercatorum pararepleta and $D$. paranaensis based on a morphometric analysis of the wings of two sympatric populations of these species. The heritability under laboratory and field conditions from the parameters generated was also estimated. The wing shape variation was quantified by superimposing an ellipse on the wing. Multivariate analysis was used to obtain the pattern of variation in 
each population and to discriminate between these cryptic species.

\section{Materials and methods}

\section{Flies}

$D$. mercatorum and D. paranaensis were collected in December 2000 using banana and orange baits in the Pé-de-Gigante reserve between $21^{\circ} 37^{\prime} 30^{\prime \prime} S$ and $47^{\circ} 37^{\prime} 30^{\prime \prime} \mathrm{W}$, in the State of São Paulo, Brazil. Females were placed in shell vials with fresh culture medium and maintained for 3 days at $25^{\circ} \mathrm{C}$ to establish isofemale lines. On average, the samples consisted of four $F_{1}$ females from each isofemale line. Males were identified by the external morphology of their genitalia. Since females were considered morphologically identical, they were indirectly identified by the morphology of the genitalia of their $F_{1}$ male offspring. The total sample consisted of six groups, that is, three from each species. The D. mercatorum sample consisted of 45 field-caught males, 49 field-caught females and $189 \mathrm{~F}_{1}$ lab females (three to four daughters from each isofemale line) while the D. paranaensis sample was made up of 44 field-caught males, 49 field-caught females and 198 lab females (four to five daughters from each isofemale line).

\section{Wing measurements}

Morphometric analysis of the wings used 17 parameters provided by the ellipse method developed by Klaczko and Bitner-Mathé (1990). A complete description of this method is given by Bitner-Mathé and Klaczko (1999b). In brief, this method finds the best fit of an ellipse around the wing and produces parameters based on the geometric properties of this ellipse. A measure of wing size $\left(W_{\mathrm{SI}}\right)$ can be obtained from the geometric mean of two radii $(a$ and $b)$ of the ellipse $\left(W_{\mathrm{SI}}=\sqrt{ } a b\right)$. The ratio $b / a$ is a measure of an ellipse outline shape $\left(W_{\mathrm{SH}}\right)$ independent of size. The method also uses the extremities of both transversal and longitudinal veins of the wing to establish the placement of 10 landmarks $(\mathrm{A}-\mathrm{J})$ defined by the angle $(\theta)$ between a line joining the landmark to the center of the ellipse and the line that defines the longest radius $(a)$ of the ellipse. The position of the internal landmarks (F-J) also takes into account the distance $(D)$ of the landmark from the center of the ellipse. These five landmarks in the interior of the wing, including the extremities of the transversal veins, were adjusted for size using the relationship $D / W_{\mathrm{SI}}$. Thus, the parameters $D_{\mathrm{F}}-D_{\mathrm{J}}$ became dimensionless descriptors of the internal landmark placements.

The right wing of each fly was mounted on a microscope slide and photographed using a video camera attached to a stereo microscope at $\times 16$ magnification. Cartesian coordinates of 30 points along the margin of each wing and of the 10 landmarks were obtained using the TpsDig software (version 1.26, Rohlf, 1998). These data were entered into the ASALK program (Bitner-Mathé and Klaczko, 1999b), which calculates the radii of the ellipses, the angles $\theta$ and the distance $D$. The repeatability of the 17 wing parameters was calculated on a subsample of $D$. mercatorum (three measurements on 90 individuals) using the equation provided in Falconer and Mackay (1996). The average repeatability for the 17 wing parameters was $96 \% \pm 0.5 \%$, but when the correc- tion recommended by Lessells and Boag (1987) was applied, the average repeatability was $90 \% \pm 1 \%$.

\section{Heritability estimates}

For each species, field-caught females and lab females were used to estimate cross-environment and laboratory heritabilities. Natural heritability should ideally be obtained from relatives in the wild, an impractical approach in Drosophila. In an appendix to Coyne and Beecham (1987), Lande showed that an alternative method for determining 'natural' heritability was to obtain cross-environment estimates by regressing the trait values of lab-reared offspring on their field-caught parents. However, this approach is only reliable when the estimated additive genetic variance is similar in different environments and when there is no genotypeenvironment interaction. Riska et al (1989) extended Lande's approach and showed how a lower bound of heritability could be estimated in the wild, even when Lande's condition is not met. This approach also allows the identification of possible sources of bias in estimates of natural heritability.

The cross-environment heritability, representing the natural heritability, was estimated using parent-offspring regression $\left(b_{\mathrm{OP}}\right)$ between field-caught females and the mean values for their lab female daughters. This heritability estimate was obtained by doubling the regression coefficient (ie $2 b_{(\mathrm{Ol} \text {.Pn) }}$ ) because only one parent was used in the analysis. Differences in the additive genetic variance between field and laboratory or genotype-environment interaction can bias the estimate of cross-environment heritability in either direction (Lande in Coyne and Beecham, 1987), thereby resulting in differences between this heritability and laboratory heritability estimates. A second heritability in the wild $\left(h_{\mathrm{V}}^{2}\right)$, assuming no genotype-environment interaction, was estimated as the ratio of the additive genetic variance in the laboratory to the phenotypic variance in the wild (Riska et al, 1989). The $h_{V}^{2}$ values were used to identify possible bias in the cross-environment heritability estimates by calculating the $h_{\mathrm{V}}^{2} / h_{(\mathrm{OIPn})}^{2}$ ratio $(k)$. Heritability in the laboratory was estimated using fullsib intraclass correlation based on the partition of the variance of the lab females for the between and within isofemale line components. The heritability estimate was obtained by doubling the correlation coefficient (Falconer and Mackay, 1996). The cross-environment heritability represented narrow-sense heritability $\left(V_{\mathrm{A}} / V_{\mathrm{P}}\right)$, while the laboratory heritability was inflated by variance due to dominance, and by common environment $\left(2\left[1 / 2 V_{\mathrm{A}}+1 /\right.\right.$ $\left.\left.4 V_{\mathrm{D}}+V_{\mathrm{Ec}}\right] / V_{\mathrm{P}}\right)$. The statistical probabilities for the heritability estimates were adjusted using the sequential Bonferroni correction (Holm, 1979).

\section{Multivariate statistical analysis}

Since all of the variables followed a normal distribution, multivariate analysis was carried out using the original values. Differences between sexes, environments and species were tested using one-way MANOVA. The significant univariate $F$ values were used to identify the wing parameters in the model that contributed most to the difference between groups. Principal component analysis (PCA), using a correlation matrix, was performed separately on the values obtained for the 
field-caught females and field-caught males of $D$. mercatorum and $D$. paranaensis in order to identify the correlation pattern between the measures and assess how this behaved for each species. Only principal components with an eigenvalue greater than 1.00 were used in the analysis. To verify the degree of separation between $D$. mercatorum and D. paranaensis, discriminate multivariate analysis (DA) of the wing parameters was performed separately on field-caught females, fieldcaught males and lab females. A classification function generated for each group was used to obtain a matrix of the percent of correctly classified individuals in each species. Furthermore, the efficiency of the classification functions generated for D. mercatorum and D. paranaensis was verified using a cross-validation test, in which the classification functions derived from field-caught females were used to classify lab females and vice versa.

\section{Results}

\section{Descriptive statistics}

The mean values and phenotypic variances for the wing traits analyzed in field-caught females, field-caught males and lab females of $D$. mercatorum and $D$. paranaensis are shown in Table 1 . As the environmental conditions for the lab females in laboratory culture were very similar, the phenotypic variance of this group was expected to be less than that of their mothers reared in the field. This was indeed the case for most of the $D$. mercatorum parameters (11/17), but was true for only a few of the $D$. paranaensis parameters (5/17). For both species, the $W_{\mathrm{SH}}$ parameter showed more variation in field-caught flies than in their laboratory counterparts. Variation in wing size, as measured by the parameter $W_{\mathrm{SI}}$, was greater in the field only for D. mercatorum.

\section{Multivariate analysis of variance}

One-way MANOVA of wing parameters showed significant differences between sexes, environments and species, and the univariate $\mathrm{F}$ values showed which parameters contributed most to the differences between groups (Table 2$)$. For both species, wing size $\left(W_{\mathrm{SI}}\right)$ was the most important parameter for the difference between sexes, whereas the parameters $\theta_{\mathrm{G}}$ and $\theta_{\mathrm{H}}$ were the most important for differences between environments in $D$. mercatorum and $D$. paranaensis, respectively. The parameters $D_{\mathrm{I}}, \theta_{\mathrm{H}}, W_{\mathrm{SI}}$ and $D_{\mathrm{H}}$ contributed most to the differences between $D$. mercatorum and $D$. paranaensis in the groups field-caught females and lab females. For the field-caught males, the parameters $D_{\mathrm{I}}, D_{\mathrm{H}}, D_{\mathrm{F}}$ and $\theta_{\mathrm{I}}$ contributed most to the differences between species. In the three groups of flies, the parameter $D_{\mathrm{I}}$, which represented the position of the transversal wing vein, was the most important for species differences.

\section{Heritability}

Most of the parameters extracted from the wings by the ellipse method had high heritability, indicating a substantial additive genetic component in the phenotypic variance (Table 3). The cross-environment and lab heritabilities were high and significant for both species for parameters that described the position of the transversal wing veins. D. mercatorum showed high cross-environment and lab heritabilities for the wing outline shape $\left(W_{\mathrm{SH}}\right)$ and significant cross-environment heritability only for the parameters that described the position of longitudinal wing veins $\left(\theta_{\mathrm{A}}, \theta_{\mathrm{B}}, \theta_{\mathrm{D}}\right.$ and $\left.\theta_{\mathrm{J}}\right)$. In $D$. paranaensis, wing shape $\left(W_{\mathrm{SH}}\right)$ showed no significant cross-environment heritability. The heritability of wing size $\left(W_{\mathrm{SI}}\right)$ for $D$. paranaensis and $D$. mercatorum was high and significant only in the laboratory. Most of the parameters in $D$. mercatorum showed greater crossenvironment heritability than laboratory heritability, whereas in D. paranaensis the situation was the opposite. Bias from genotype-environment interactions or dissimilar additive genetic variance between both environments could account for these differences.

Another contrast between D. mercatorum and $D$. paranaensis concerned the $k$ ratio. In $D$. mercatorum,

Table 1 Descriptive statistics for 17 wing parameters in Drosophila mercatorum and Drosophila paranaensis

\begin{tabular}{|c|c|c|c|c|c|c|c|c|c|c|c|c|}
\hline \multirow[t]{3}{*}{ Parameter } & \multicolumn{12}{|c|}{ Mean $\pm S E V_{\mathrm{P}}\left(\times 10^{-3}\right)$} \\
\hline & \multicolumn{6}{|c|}{ D. mercatorum } & \multicolumn{6}{|c|}{ D. paranaensis } \\
\hline & \multicolumn{2}{|c|}{$\begin{array}{l}\text { Field-caught females } \\
\qquad(\mathrm{n}=49)\end{array}$} & \multicolumn{2}{|c|}{$\begin{array}{l}\text { Field-caught males } \\
\qquad(\mathrm{n}=45)\end{array}$} & \multicolumn{2}{|c|}{$\begin{array}{l}\text { Lab females } \\
\quad(\mathrm{n}=189)\end{array}$} & \multicolumn{2}{|c|}{$\begin{array}{l}\text { Field-caught females } \\
\qquad(\mathrm{n}=49)\end{array}$} & \multicolumn{2}{|c|}{$\begin{array}{l}\text { Field-caught males } \\
\qquad(\mathrm{n}=44)\end{array}$} & \multicolumn{2}{|c|}{$\begin{array}{l}\text { Lab females } \\
\quad(\mathrm{n}=198)\end{array}$} \\
\hline$\theta_{\mathrm{A}}$ & $0.730 \pm 0.006$ & 2.36 & $0.697 \pm 0.007$ & 2.65 & $0.762 \pm 0.003$ & 2.96 & $0.724 \pm 0.006$ & 2.42 & $0.716 \pm 0.005$ & 1.37 & $0.733 \pm 0.003$ & 2.52 \\
\hline$\theta_{\mathrm{B}}$ & $2.758 \pm 0.005$ & 1.42 & $2.746 \pm 0.004$ & 0.90 & $2.774 \pm 0.002$ & 0.93 & $2.755 \pm 0.004$ & 1.14 & $2.747 \pm 0.004$ & 0.93 & $2.768 \pm 0.002$ & 0.93 \\
\hline$\theta_{\mathrm{C}}$ & $3.168 \pm 0.002$ & 0.29 & $3.169 \pm 0.003$ & 0.42 & $3.174 \pm 0.001$ & 0.26 & $3.167 \pm 0.002$ & 0.27 & $3.168 \pm 0.003$ & 0.42 & $3.170 \pm 0.001$ & 0.26 \\
\hline$\theta_{\mathrm{D}}$ & $3.339 \pm 0.003$ & 0.44 & $3.347 \pm 0.003$ & 0.50 & $3.339 \pm 0.001$ & 0.30 & $3.338 \pm 0.002$ & 0.36 & $3.348 \pm 0.003$ & 0.51 & $3.336 \pm 0.001$ & 0.33 \\
\hline$\theta_{\mathrm{E}}$ & $4.225 \pm 0.011$ & 6.15 & $4.269 \pm 0.011$ & 6.10 & $4.205 \pm 0.005$ & 4.87 & $4.237 \pm 0.009$ & 4.63 & $4.233 \pm 0.012$ & 7.17 & $4.202 \pm 0.005$ & 5.69 \\
\hline$\theta_{\mathrm{F}}$ & $0.600 \pm 0.008$ & 3.55 & $0.535 \pm 0.007$ & 2.38 & $0.633 \pm 0.004$ & 3.86 & $0.596 \pm 0.007$ & 2.88 & $0.559 \pm 0.006$ & 2.08 & $0.615 \pm 0.004$ & 4.26 \\
\hline$\theta_{\mathrm{G}}$ & $0.402 \pm 0.007$ & 2.70 & $0.356 \pm 0.006$ & 1.67 & $0.435 \pm 0.003$ & 2.62 & $0.402 \pm 0.005$ & 1.57 & $0.375 \pm 0.005$ & 1.15 & $0.426 \pm 0.003$ & 2.49 \\
\hline$\theta_{\mathrm{H}}$ & $3.442 \pm 0.013$ & 9.06 & $3.569 \pm 0.015$ & 11.38 & $3.416 \pm 0.005$ & 5.00 & $3.507 \pm 0.007$ & 3.18 & $3.536 \pm 0.011$ & 6.32 & $3.473 \pm 0.004$ & 3.89 \\
\hline$\theta_{\mathrm{I}}$ & $4.385 \pm 0.016$ & 13.24 & $4.493 \pm 0.016$ & 11.80 & $4.336 \pm 0.008$ & 12.51 & $4.367 \pm 0.015$ & 11.64 & $4.403 \pm 0.019$ & 16.24 & $4.310 \pm 0.011$ & 12.43 \\
\hline$\theta_{\mathrm{J}}$ & $0.392 \pm 0.004$ & 1.03 & $0.368 \pm 0.005$ & 1.13 & $0.412 \pm 0.002$ & 1.10 & $0.397 \pm 0.003$ & 0.78 & $0.379 \pm 0.004$ & 0.71 & $0.408 \pm 0.002$ & 0.87 \\
\hline $\mathrm{D}_{\mathrm{F}}$ & $0.493 \pm 0.005$ & 1.33 & $0.516 \pm 0.004$ & 0.80 & $0.472 \pm 0.002$ & 1.39 & $0.461 \pm 0.004$ & 1.09 & $0.489 \pm 0.005$ & 1.47 & $0.451 \pm 0.002$ & 1.59 \\
\hline $\mathrm{D}_{\mathrm{G}}$ & $0.455 \pm 0.006$ & 1.84 & $0.491 \pm 0.004$ & 1.09 & $0.435 \pm 0.002$ & 1.61 & $0.436 \pm 0.005$ & 1.25 & $0.465 \pm 0.006$ & 1.74 & $0.423 \pm 0.003$ & 1.87 \\
\hline $\mathrm{D}_{\mathrm{H}}$ & $0.209 \pm 0.005$ & 1.55 & $0.185 \pm 0.004$ & 0.83 & $0.225 \pm 0.002$ & 1.31 & $0.237 \pm 0.004$ & 0.85 & $0.221 \pm 0.006$ & 1.56 & $0.252 \pm 0.002$ & 1.23 \\
\hline $\mathrm{D}_{\mathrm{I}}$ & $0.344 \pm 0.002$ & 0.34 & $0.342 \pm 0.002$ & 0.34 & $0.346 \pm 0.001$ & 0.36 & $0.375 \pm 0.002$ & 0.40 & $0.368 \pm 0.003$ & 0.15 & $0.376 \pm 0.001$ & 0.33 \\
\hline $\mathrm{D}_{\mathrm{J}}$ & $0.996 \pm 0.005$ & 1.53 & $1.014 \pm 0.007$ & 2.56 & $0.968 \pm 0.003$ & 2.29 & $0.969 \pm 0.005$ & 1.55 & $0.993 \pm 0.005$ & 1.47 & $0.963 \pm 0.003$ & 2.05 \\
\hline $\mathrm{W}_{\mathrm{SI}}$ & $0.848 \pm 0.004$ & 1.03 & $0.769 \pm 0.004$ & 0.88 & $0.860 \pm 0.002$ & 0.79 & $0.871 \pm 0.003$ & 0.48 & $0.785 \pm 0.004$ & 1.04 & $0.882 \pm 0.001$ & 0.76 \\
\hline $\mathrm{W}_{\mathrm{SH}}$ & $0.430 \pm 0.002$ & 0.29 & $0.445 \pm 0.001$ & 0.12 & $0.424 \pm 0.001$ & 0.20 & $0.440 \pm 0.002$ & 0.33 & $0.446 \pm 0.002$ & 0.29 & $0.433 \pm 0.001$ & 0.24 \\
\hline
\end{tabular}

The values $\theta_{\mathrm{A}}-\theta_{\mathrm{J}}$ are in radians, $W_{\mathrm{SI}}$ is in millimeters, $D_{\mathrm{F}}-D_{\mathrm{J}}$ are ratios and $W_{\mathrm{SH}}$ is a coefficient with no units. 
Table 2 One-way MANOVA for groups within and between species

\begin{tabular}{|c|c|c|c|c|c|}
\hline Groups & Wilks' $\lambda$ & $\mathrm{F}$ & d.f. & $\mathrm{P}$ & Model \\
\hline \multicolumn{6}{|l|}{ D. mercatorum } \\
\hline Field-caught females $v s$ field-caught males & 0.286 & 11.12 & 17,76 & 0.0000 & $W_{\mathrm{SI}}, \theta_{\mathrm{H}}, \theta_{\mathrm{F}}, W_{\mathrm{SH}}$ \\
\hline Field-caught females vs lab females & 0.865 & 2.04 & 17,220 & 0.0116 & $\theta_{\mathrm{G}}, \theta_{\mathrm{A}}, \theta_{\mathrm{J}}, D_{\mathrm{J}}$ \\
\hline \multicolumn{6}{|l|}{ D. paranaensis } \\
\hline Field-caught females $v$ s field-caught males & 0.218 & 15.97 & 17,76 & 0.0000 & $W_{\mathrm{SI}}, D_{\mathrm{F}}, D_{\mathrm{G}}, \theta_{\mathrm{F}}$ \\
\hline Field-caught females vs lab females & 0.781 & 3.81 & 17,231 & 0.0000 & $\theta_{\mathrm{H}}, \theta_{\mathrm{I}}, \theta_{\mathrm{G}}, \theta_{\mathrm{E}}$ \\
\hline \multicolumn{6}{|l|}{ D. mercatorum vs D. paranaensis } \\
\hline Field-caught females & 0.205 & 18.48 & 17,81 & 0.0000 & $D_{\mathrm{I}}, \theta_{\mathrm{H}}, W_{\mathrm{SI}}, D_{\mathrm{H}}$ \\
\hline Lab females & 0.221 & 76.51 & 17,370 & 0.0000 & $D_{\mathrm{I}}, \theta_{\mathrm{H}}, W_{\mathrm{SI}}, D_{\mathrm{H}}$ \\
\hline Field-caught males & 0.516 & 3.91 & 17,71 & 0.0000 & $D_{\mathrm{I}}, D_{\mathrm{H}}, D_{\mathrm{F}}, \theta_{\mathrm{I}}$ \\
\hline
\end{tabular}

The model column shows the four wing parameters that contributed most to the difference between groups.

Table 3 Heritability estimates for D. mercatorum and D. paranaensis wing parameters in the field $\left(h_{(\mathrm{OlPn})}^{2}\right)$ and in the laboratory $\left(h_{\mathrm{lab}}^{2}\right)$, and assuming no genotype-environment interaction $\left(h_{\mathrm{V}}^{2}\right)$

\begin{tabular}{|c|c|c|c|c|c|c|c|c|}
\hline \multicolumn{5}{|c|}{ D. marcatorum } & \multicolumn{4}{|c|}{ D. paranaensis } \\
\hline Parameter & $\mathrm{h}^{2}{ }_{(\mathrm{OlP} n)} \pm S E$ & $\mathrm{~h}^{2}{ }_{l a b} \pm S E$ & $\mathrm{~h}_{V}^{2}$ & $\mathrm{k}$ & $\mathrm{h}^{2}(\mathrm{OlP} n) \pm S E$ & $\mathrm{~h}^{2} l a b \pm S E$ & $\mathrm{~h}_{V}^{2}$ & $\mathrm{k}$ \\
\hline$\theta_{\mathrm{A}}$ & $0.53 \pm 0.18^{\mathrm{a}}$ & $0.33 \pm 0.15^{\mathrm{a}}$ & 0.41 & 0.7 & $0.44 \pm 0.19 \mathrm{~ns}$ & $0.59 \pm 0.15^{\mathrm{a}}$ & 0.62 & 1.4 \\
\hline$\theta_{\mathrm{B}}^{\mathrm{A}}$ & $0.28+0.10^{\mathrm{a}}$ & $-0.05+0.11 \mathrm{NS}$ & -0.03 & 0.1 & $0.29+0.15 \mathrm{NS}$ & $0.37+0.14^{\mathrm{a}}$ & 0.30 & 1.0 \\
\hline$\theta_{\mathrm{C}}$ & $0.36 \pm 0.13 \mathrm{NS}$ & $0.02 \pm 0.12 \mathrm{NS}$ & 0.02 & 0.0 & $0.05 \pm 0.15 \mathrm{NS}$ & $0.18 \pm 0.13 \mathrm{NS}$ & 0.17 & 3.4 \\
\hline$\theta_{\mathrm{D}}$ & $0.46 \pm 0.14^{\mathrm{a}}$ & $0.10 \pm 0.13 \mathrm{NS}$ & 0.07 & 0.1 & $0.06 \pm 0.15 \mathrm{NS}$ & $0.18 \pm 0.13 \mathrm{NS}$ & 0.17 & 2.7 \\
\hline$\theta_{\mathrm{E}}$ & $0.32 \pm 0.13 \mathrm{NS}$ & $0.00 \pm 0.12 \mathrm{NS}$ & 0.00 & 0.0 & $0.40 \pm 0.19 \mathrm{NS}$ & $0.40 \pm 0.14^{\mathrm{a}}$ & 0.50 & 1.2 \\
\hline$\theta_{\mathrm{F}}$ & $0.56 \pm 0.17^{\mathrm{a}}$ & $0.42 \pm 0.15^{\mathrm{a}}$ & 0.46 & 0.8 & $0.78 \pm 0.24^{\mathrm{a}}$ & $0.88 \pm 0.15^{\mathrm{a}}$ & 1.32 & 1.6 \\
\hline$\theta_{\mathrm{G}}$ & $0.52+0.16^{\mathrm{a}}$ & $0.36+0.15^{\mathrm{a}}$ & 0.34 & 0.6 & $0.80+0.25^{\mathrm{a}}$ & $0.90+0.15^{\mathrm{a}}$ & 1.44 & 1.7 \\
\hline$\theta_{\mathrm{H}}$ & $0.40 \pm 0.12^{\mathrm{a}}$ & $0.40 \pm 0.15^{\mathrm{a}}$ & 0.22 & 0.5 & $0.36 \pm 0.12 \mathrm{NS}$ & $0.56 \pm 0.15^{\mathrm{a}}$ & 0.69 & 1.9 \\
\hline$\theta_{\mathrm{I}}$ & $0.53 \pm 0.15^{\mathrm{a}}$ & $0.26 \pm 0.14 \mathrm{NS}$ & 0.25 & 0.4 & $0.41 \pm 0.19 \mathrm{NS}$ & $0.59 \pm 0.15^{\mathrm{a}}$ & 0.63 & 1.5 \\
\hline$\theta_{\mathrm{I}}$ & $0.57 \pm 0.16^{\mathrm{a}}$ & $0.33 \pm 0.15^{\mathrm{a}}$ & 0.35 & 0.6 & $0.45 \pm 0.21 \mathrm{NS}$ & $0.71 \pm 0.15^{\mathrm{a}}$ & 0.80 & 1.7 \\
\hline$D_{\mathrm{F}}$ & $0.24 \pm 0.18 \mathrm{NS}$ & $0.40 \pm 0.15^{\mathrm{a}}$ & 0.42 & 1.7 & $0.95 \pm 0.23^{a}$ & $0.98 \pm 0.14^{\mathrm{a}}$ & 1.45 & 1.5 \\
\hline$D_{\mathrm{G}}$ & $0.31+0.18 \mathrm{NS}$ & $0.41+0.15^{\mathrm{a}}$ & 0.36 & 1.1 & $1.01+0.24^{\mathrm{a}}$ & $1.05+0.14^{\mathrm{a}}$ & 1.60 & 1.5 \\
\hline$D_{\mathrm{H}}$ & $0.57 \pm 0.16^{\mathrm{a}}$ & $0.53 \pm 0.15^{\mathrm{a}}$ & 0.45 & 0.7 & $0.68 \pm 0.24 \mathrm{NS}$ & $0.88 \pm 0.15^{\mathrm{a}}$ & 1.29 & 1.8 \\
\hline$D_{\mathrm{I}}$ & $0.50 \pm 0.18 \mathrm{NS}$ & $0.42 \pm 0.15^{\mathrm{a}}$ & 0.02 & 0.0 & $0.41 \pm 0.16 \mathrm{NS}$ & $0.58 \pm 0.15^{\mathrm{a}}$ & 0.48 & 1.1 \\
\hline$D_{\mathrm{I}}$ & $0.44 \pm 0.20 \mathrm{NS}$ & $0.30 \pm 0.14$ NS & 0.44 & 0.9 & $0.64 \pm 0.22 \mathrm{NS}$ & $0.72 \pm 0.15^{\mathrm{a}}$ & 0.96 & 1.5 \\
\hline$W_{\mathrm{SI}}$ & $0.13 \pm 0.19 \mathrm{NS}$ & $0.87 \pm 0.15^{\mathrm{a}}$ & 0.66 & 4.8 & $0.42 \pm 0.15 \mathrm{NS}$ & $0.95 \pm 0.14^{\mathrm{a}}$ & 2.22 & 5.2 \\
\hline$W_{\mathrm{SH}}$ & $0.45+0.14^{\mathrm{a}}$ & $0.49+0.15^{\mathrm{a}}$ & 0.34 & 0.7 & $0.16+0.28 \mathrm{NS}$ & $0.58+0.15^{\mathrm{a}}$ & 0.29 & 1.7 \\
\hline
\end{tabular}

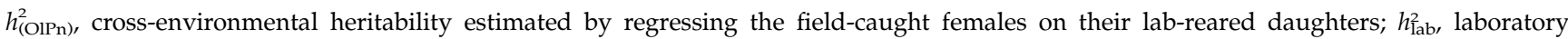
heritability estimated through full-sib intraclass correlations; $h_{\mathrm{V}}^{2}$, approximation of heritability in the wild; $k=h_{\mathrm{V}}^{2} / h_{(\mathrm{OlPn})}^{2}$ ratio. See text for explanations.

aSignificant at the 5\% level after sequential Bonferroni correction (Holm, 1979).

NS, not significant.

$k$ for most parameters was less than one, whereas in D. paranaensis the opposite was true. A value of $k<1$ indicated that additive genetic variance was greater in the wild than in the laboratory. Thus, for parameters with $k<1, h_{\mathrm{V}}^{2}$ was interpreted as the lower bound for natural heritability, with $h_{(\mathrm{OIPn})}^{2}$ being underestimated (Riska et al, 1989). In contrast, for parameters with $k>1$, no conclusion could be drawn about the relative magnitudes of the genetic variances in the two environments. The parameters $D_{\mathrm{G}}$ and $D_{\mathrm{J}}$ in $D$. mercatorum and the parameters $\theta_{\mathrm{B}}, \theta_{\mathrm{D}}$ and $D_{\mathrm{I}}$ in $D$. paranaensis had a $k$ ratio close to one, which suggested similar additive genetic variance in the two environments and no genotype-environment interaction.

\section{Principal components analysis}

For D. mercatorum, PCA showed that the variation in the 17 wing parameters could be summarized into four principal components, PC1, PC2, PC3 and PC4, which accounted for 46, 25, 7 and $6 \%$, respectively, of the total normalized variance of the parameters. In D. paranaensis, the total variance could be summarized into three principal components, PC1, PC2 and PC3, which respectively accounted for 39, 29 and $8 \%$ of the total normalized variance. Table 4 shows the loading values obtained by PCA for each species. These values represent the correlation coefficients for each parameter with each principal component and, indirectly, the correlation between parameters (Bitner-Mathé and Klaczko, 1999b). The principal component loading values of the morphometric parameters were positive and negative, indicating that these PCs represent wing shape functions in a general sense (Bookstein et al, 1985). Even though the total variation in the wings of $D$. mercatorum was summarized in a greater number of principal components than was the case for $D$. paranaensis, the two species showed the same general pattern of variation. The reversed signs between the loading values of $D$. mercatorum and D. paranaensis resulted from a technical 
Table 4 Principal component coefficients obtained from the correlation matrix of Drosophila mercatorum and Drosophila paranaensis wing parameters

\begin{tabular}{|c|c|c|c|c|c|c|c|}
\hline \multirow[t]{2}{*}{ Parameter } & \multicolumn{4}{|c|}{ D. mercatorum } & \multicolumn{3}{|c|}{ D. paranaensis } \\
\hline & $P C 1$ & $P C 2$ & PC3 & PC4 & $P C 1$ & PC2 & PC3 \\
\hline$\theta_{\mathrm{A}}$ & -0.778 & 0.540 & 0.126 & -0.021 & 0.622 & 0.591 & 0.210 \\
\hline$\theta_{\mathrm{B}}$ & -0.388 & 0.587 & -0.473 & 0.357 & 0.424 & 0.556 & -0.527 \\
\hline$\theta_{\mathrm{C}}$ & 0.032 & 0.879 & -0.051 & 0.288 & 0.206 & 0.783 & -0.299 \\
\hline$\theta_{\mathrm{D}}$ & 0.256 & 0.838 & 0.163 & 0.230 & -0.019 & 0.828 & -0.093 \\
\hline$\theta_{\mathrm{E}}$ & 0.374 & 0.847 & 0.011 & 0.051 & -0.204 & 0.882 & 0.074 \\
\hline$\theta_{\mathrm{F}}$ & -0.925 & 0.242 & 0.044 & -0.109 & 0.912 & 0.233 & 0.207 \\
\hline$\theta_{\mathrm{G}}$ & -0.866 & 0.254 & 0.084 & -0.107 & 0.836 & 0.342 & 0.161 \\
\hline$\theta_{\mathrm{H}}$ & 0.740 & 0.505 & 0.169 & 0.346 & -0.616 & 0.564 & 0.180 \\
\hline$\theta_{\mathrm{I}}$ & 0.669 & 0.669 & -0.037 & -0.169 & -0.492 & 0.808 & 0.063 \\
\hline$\theta_{\mathrm{J}}$ & -0.777 & 0.516 & 0.111 & -0.091 & 0.702 & 0.498 & 0.255 \\
\hline $\mathrm{D}_{\mathrm{F}}$ & 0.886 & -0.128 & -0.152 & 0.199 & -0.914 & 0.011 & -0.033 \\
\hline $\mathrm{D}_{\mathrm{G}}$ & 0.926 & -0.53 & -0.083 & 0.149 & -0.916 & 0.055 & -0.055 \\
\hline $\mathrm{D}_{\mathrm{H}}$ & -0.778 & -0.277 & 0.133 & 0.001 & 0.643 & -0.607 & -0.208 \\
\hline $\mathrm{D}_{\mathrm{I}}$ & -0.177 & -0.390 & 0.564 & 0.647 & 0.369 & -0.609 & 0.338 \\
\hline $\mathrm{D}_{\mathrm{J}}$ & 0.816 & -0.230 & -0.183 & 0.178 & -0.829 & -0.105 & -0.157 \\
\hline$W_{S I}$ & -0.690 & -0.154 & -0.248 & 0.151 & 0.546 & -0.075 & -0.155 \\
\hline $\mathrm{W}_{\mathrm{SH}}$ & 0.505 & 0.152 & 0.724 & -0.183 & -0.383 & 0.107 & 0.806 \\
\hline
\end{tabular}

Table 5 The percentage of successful classification obtained by discriminant analysis carried out separately on the wing parameters of field-caught females, lab females and field-caught males of D. mercatorum and D. paranaensis

\begin{tabular}{lcc}
\hline & D. mercatorum & D. paranaensis \\
\hline Autoclassification & & \\
Field-caught females & $98 \%(49)$ & $98 \%(49)$ \\
Lab females & $95 \%(189)$ & $97.5 \%(198)$ \\
Field-caught males & $87 \%(45)$ & $82 \%(44)$ \\
Cross-validation & & \\
Field-caught females & $96 \%$ & $94 \%$ \\
Lab females & $92 \%$ & $96 \%$ \\
\hline
\end{tabular}

The sample size is shown in parentheses. Cross-validation of the autoclassification was carried out using the classification function derived from field-caught females to classify lab females and vice versa.

artifact since the rotation of the PCs is arbitrary. In both species, PC1 was correlated with the wing size parameter $W_{\mathrm{SI}}, \mathrm{PC} 2$ showed that the variation in the parameters $\theta_{\mathrm{A}}$, $\theta_{\mathrm{B}}, \theta_{\mathrm{C}}, \theta_{\mathrm{D}}$ and $\theta_{\mathrm{E}}$ (related to the extremities of the longitudinal wing veins at the wing edge) were correlated, and PC3 was correlated with $W_{\mathrm{SH}}$, the parameter for wing outline. One component, PC4, occurred only in D. mercatorum where it correlated with the parameter $D_{\mathrm{I}}$. Since the square of the loading values represents the fraction of the total variance explained by the principal component, the value of PC4 suggested that in $D$. mercatorum most of the variation in $D_{\mathrm{I}}$ $\left(0.42=0.647^{2}\right)$ was not correlated with the other parameters.

\section{Discriminant analysis}

Table 5 shows the percentages of successful autoclassification generated by discriminant analysis. The results were high and similar (95-98\%) for field-caught and lab females, but were lower for field-caught males. The cross-validation test, which was based on the classifica- tion functions derived from field-caught and lab females, confirmed the results of the autoclassification.

Figure 1 shows the distribution of the discriminant function scores for the three groups, with only one discriminate function (number of species-1) being obtained in each analysis. Separation between species was almost complete for the field-caught females and lab females, whereas for field-caught males the overlap was much larger, thus confirming the results of the autoclassification. Figure 2 shows the separation between $D$. mercatorum and D. paranaensis based on the pairs of parameters with the most weight in the differences for each group. These plots highlight the differences between the two species for the parameters related to the posterior transversal wing vein. The average ellipses of each group of D. mercatorum and D. paranaensis were extracted and superimposed as shown in Figure 3. This diagram emphasizes shape divergence since the difference in the placement of the posterior transversal vein (represented by landmarks $\mathrm{H}$ and I) was rather larger than the difference in size.

\section{Discussion}

The results of this study show that it is possible to almost completely separate the females of the sibling species $D$. mercatorum and $D$. paranaensis using morphometric analysis of their wings. The morphological divergence between $D$. mercatorum and $D$. paranaensis was attributable mainly to the position of the posterior transversal vein. In $D$. paranaensis, the posterior transversal wing vein was nearer the wing border while in $D$. mercatorum it was nearer the centre of the wing (Figure 3). Wing size $\left(W_{\mathrm{SI}}\right)$ was also important in the morphological divergence, as females of $D$. paranaensis had larger wings.

We observed high cross-environment and laboratory heritability values (average $\sim 60 \%$ ) for the wing parameters in both species. In Drosophila, morphological traits have the highest heritability values compared to other trait categories such as life history, probably because the former are less concerned with fitness (Roff and 

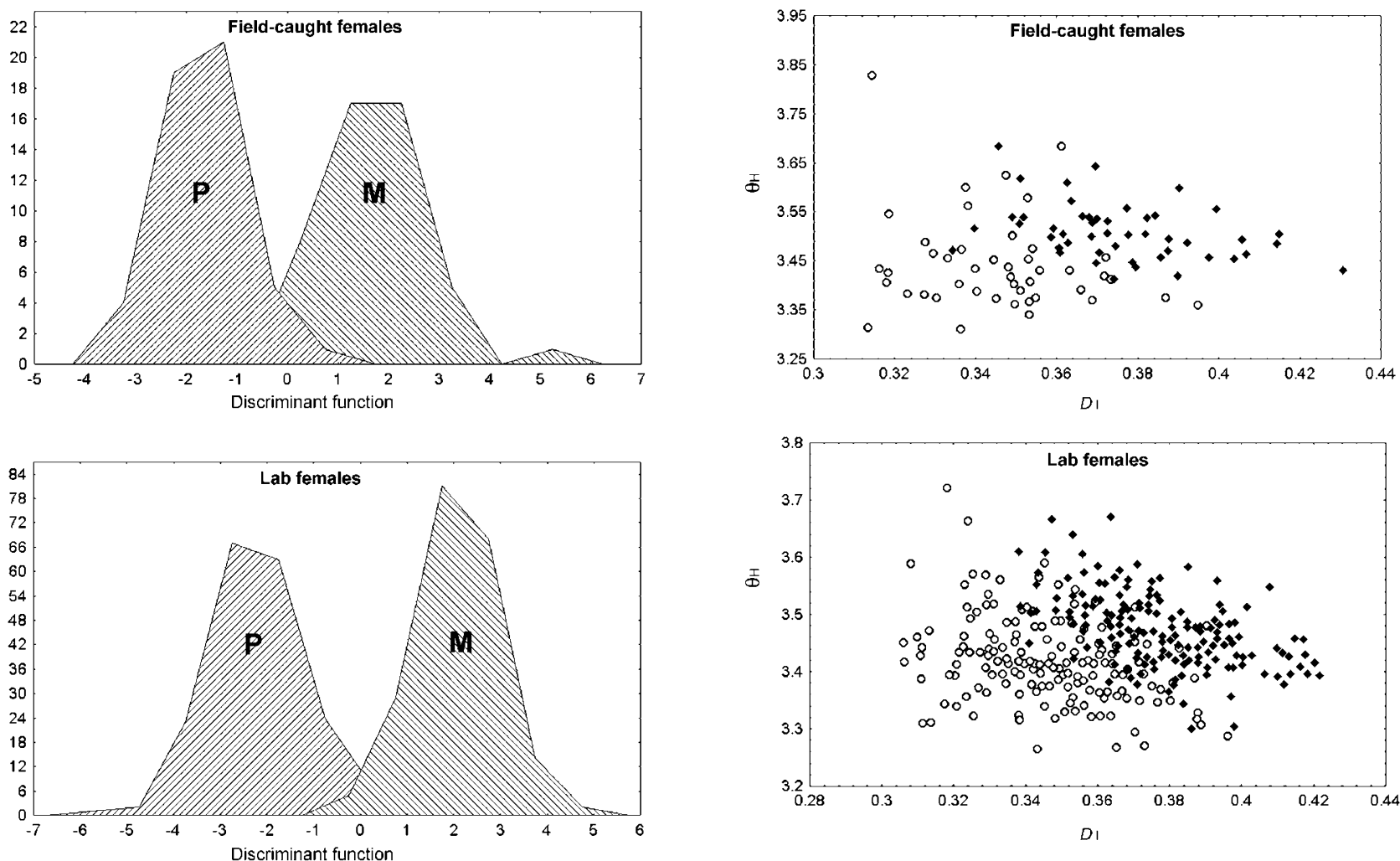

D।
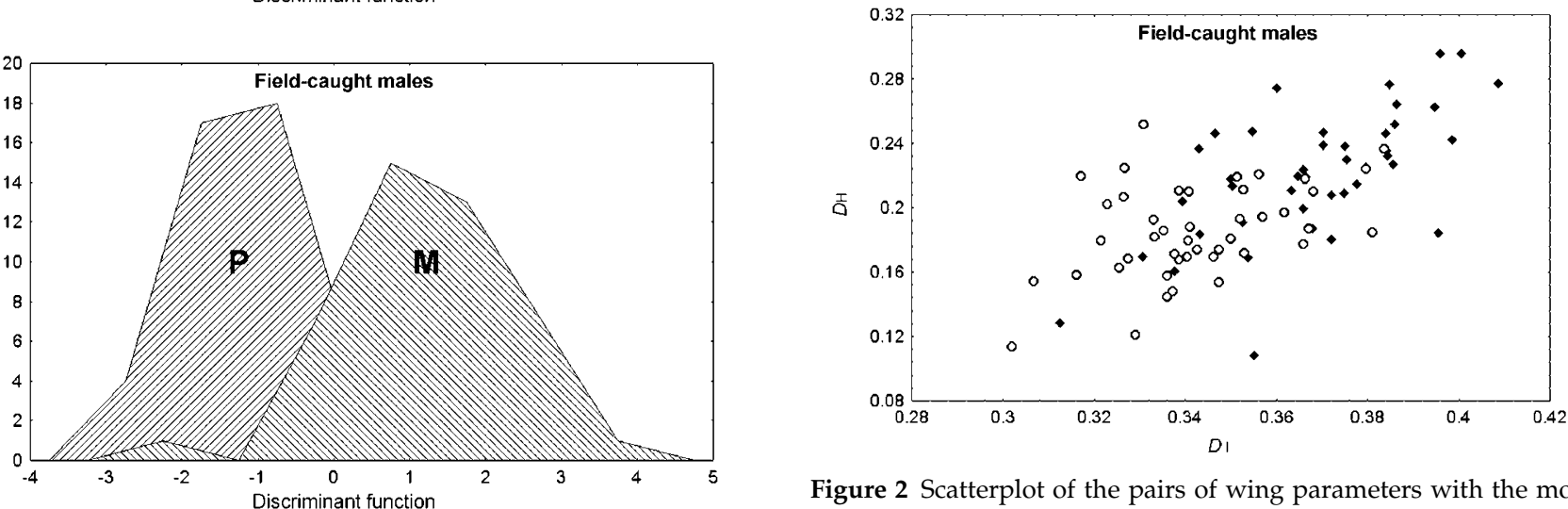

Figure 2 Scatterplot of the pairs of wing parameters with the most weight in discriminating between field-caught females, lab females and field-caught males of D. mercatorum (open circles) and $D$. paranaensis (filled diamonds).

Figure 1 Distribution of the discriminant scores for field-caught females, lab females and field-caught males. $\mathrm{M}=D$. mercatorum, $\mathrm{P}=$ D. paranaensis.

Mousseau, 1987). Hoffman and Shirriffs (2002) obtained heritability estimates for wing shape in D. serrata, measured as a ratio of wing length to the square root of wing area and referred to as wing aspect, of 0.62 for laboratory-reared flies. Gilchrist and Partridge (2001) also found high heritability estimates for wing shape in laboratory-reared D. melanogaster ( $>0.60$ ). Bitner-Mathé and Klaczko (1999c), in a study of wing shape variation in a natural population of $D$. mediopunctata using the ellipse method, obtained a heritability estimate for ellipse outline shape $\left(W_{\mathrm{SH}}\right)$ of 0.62 , whereas the heritability estimates for angles related to longitudinal veins $(\theta \mathbf{s})$ were $0.22-0.56$. These heritability estimates for shape in Drosophila, as well as our estimates, are at the upper end of the range obtained for morphological traits in Drosophila (Roff and Mousseau, 1987). Weber et al (1999; 2001) studied the polygenes in chromosomes 2 and 3 that

affect wing shape in D. melanogaster and found most of the effect on genetic variance was due to additive gene action. The high incidence of natural heritability in the wing parameters studied here suggests that a large fraction of the morphological divergence seen between $D$. mercatorum and $D$. paranaensis is due to additive effects of genes.

The occurrence of clinal variation in wing shape with latitude in Drosophila species has suggested the potential adaptive nature of this trait (Azevedo et al, 1998; Gilchrist et al, 2000; Gilchrist and Partridge, 2001; Hoffmann and Shirriffs, 2002). Gilchrist and Partridge (2001), who studied the genetic architecture of wing shape in a naturally occurring wing size cline in Australian populations of D. melanogaster, found a predominantly additive component accounting for variation. These authors suggested an evolutionary history of optimizing selection 

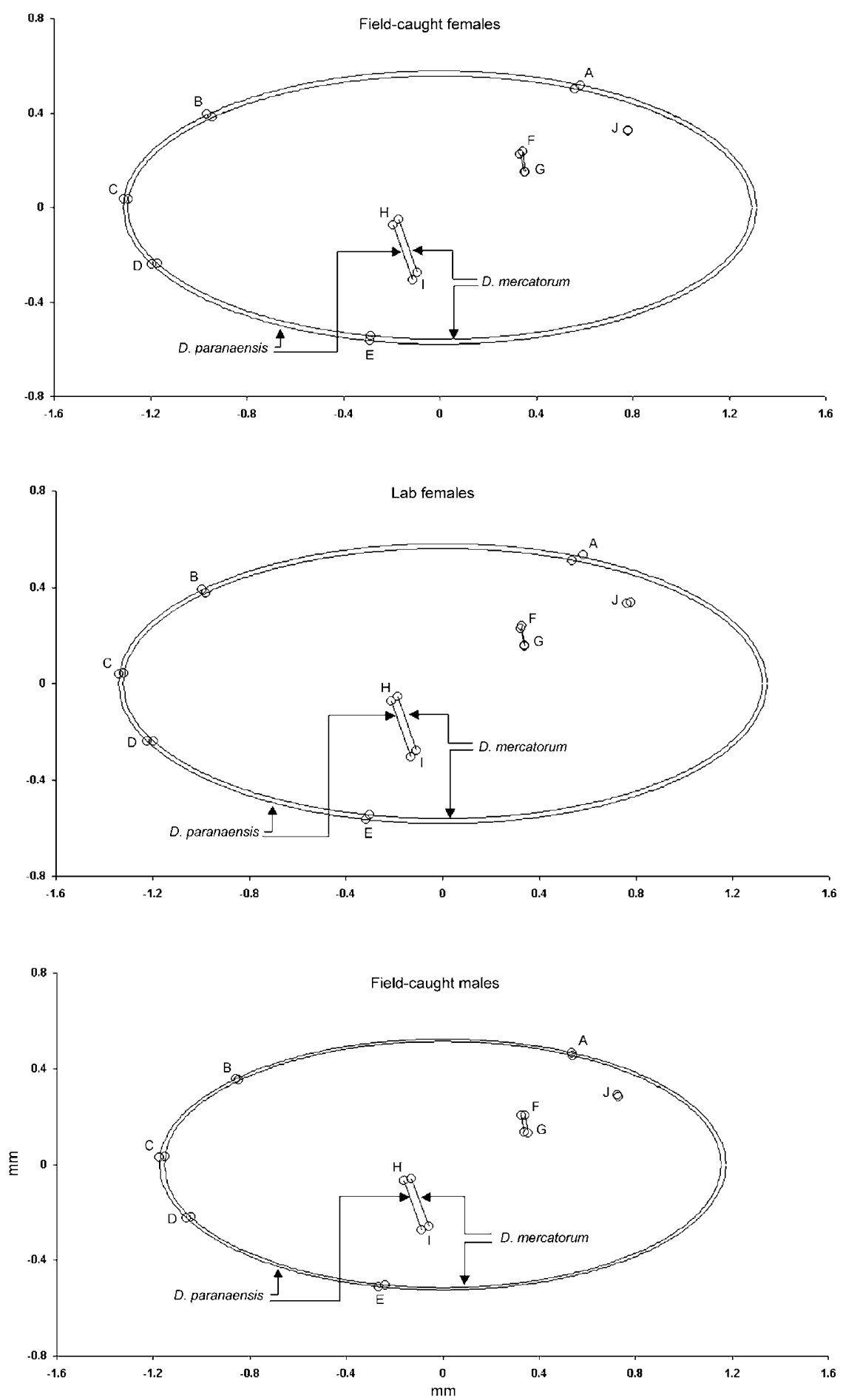

Figure 3 Superimposition of the average ellipses extracted from the data of field-caught females, lab females and field-caught males of $D$. mercatorum and D. paranaensis. The ellipses were superimposed by their origins (zero point in the Cartesian axes). The points A-J are the landmarks used as the basis of wing parameters.

for wing shape, with the variation simply representing drift around an optimum. However, the generally high heritability estimates observed in wing shape contrast with current directional or stabilizing selection pressures since classic theory predicts that traits associated with fitness will have low heritabilities because of the erosion of additive genetic variation (Falconer and Mackay, 1996). The wing shape divergence in
D. mercatorum and D. paranaensis could have resulted from past selective forces with different directions acting on genes related to this characteristic in each species, or could be correlated with the response to selection in another trait. However, more direct analyses, such as fitness experiments in controlled conditions and/or QTL analysis, are needed to clarify the causes of wing shape divergence. 
Although there was enough morphological divergence to separate $D$. mercatorum and D. paranaensis, PCA demonstrated that the pattern of morphological variation in the wings of these two species was similar, possibly because of shared restrictions in wing development pathways inherited from a common ancestor. However, this similar pattern between species was not observed in the relative magnitude of the additive genetic variance in the laboratory and field. In D. paranaensis, most of the parameters showed greater heritability in the laboratory than in the cross-environment estimates and the $k$ ratios were greater than one, whereas in $D$. mercatorum the results were the opposite. This finding suggests that the greater laboratory heritability in $D$. paranaensis was biased due to genotype-environment conditions, and that the viability of lab reared $D$. mercatorum was diminished, since the additive genetic variance in the field was greater than in the laboratory.

The ellipse method consistently discriminated between D. mercatorum and D. paranaensis females based on traits with high heritability and helped to explain the morphological divergence between these two sibling species. The information on morphological divergence and the heritability values presented in this paper should be useful for studying the genetic architecture of the morphological differences between $D$. mercatorum and D. paranaensis.

\section{Acknowledgements}

We thank Professor LB Klaczko for help with the ellipse method, statistical analysis and comments on the manuscript, PR Epifânio for technical assistance, and two anonymous reviewers for comments on the manuscript. We also thank Professor R Zucchi for help in capturing the wing images. This research was supported by FAPESP (Grant number 00/05979-5 to EM Moraes), FINEP, CNPq and USP.

\section{References}

Azevedo RBR, James AC, McCabe J, Partridge L (1998). Latitudinal variation of wing:thorax ratio and wing aspect ratio in Drosophila melanogaster. Evolution 52: 1353-1362.

Barros R (1950). A new species of the genus 'Drosophila', with discussion about speciation in the 'mercatorum' subgroup. Rev. Bras. Biol. 10: 266-278.

Bitner-Mathé BC, Klaczko LB (1999a). Size and shape heritability in natural populations of Drosophilamediopunctata: temporal and microgeographical variation. Genetica 105: 35-42.

Bitner-Mathé BC, Klaczko LB (1999b). Plasticity of Drosophila melanogaster wing morphology: effects of sex, temperature and density. Genetica 105: 203-210.

Bitner-Mathé BC, Klaczko LB (1999c). Heritability, phenotypic and genetic correlations of size and shape of Drosophila mediopunctata wings. Heredity 83: 688-696.

Bookstein F, Chernoff B, Elder R, Humphries J, Smith G, Strauss $\mathrm{R}$ (1985). Morphometrics in Evolutionary Biology. Special Publication 15. Academy of Natural Sciences: Philadelphia.

Brown KR, Shipp E (1978). Wing morphometric analysis of Australian Sarcophaginae (Diptera: Sarcophagidae). Syst. Entomol. 3: 179-188.

Carson HL (1965). Chromosomal morphism in geographically widespread species of Drosophila. In: Barker HG, Stebbins GL (eds) The Genetics of Colonizing Species. Academic Press: New York, pp 508-531.

Coyne JA, Beecham E (1987). Heritability of two morphological characters within and among natural populations of Drosophila melanogaster. Genetics 117: 727-737.

Falconer DS, Mackay TFC (1996). Introduction to Quantitative Genetics. 4th edn. Longman: Harlow.

Gilchrist AS, Azevedo RBR, Partridge L, O’Higins P (2000). Adaptation and constraint in the evolution of Drosophila melanogaster wing shape. Evol. Dev. 2: 114-124.

Gilchrist AS, Partridge L (2001). The contrasting genetic architecture of wing size and shape in Drosophila melanogaster. Heredity 86: 144-152.

Hass HL, Tolley KA (1998). Geographic variation of wing morphology in three Eurasian populations of the fruit fly, Drosophila lummei. J. Zool. 245: 197-203.

Hoffmann AA, Shirriffs J (2002). Geographic variation for wing shape in Drosophila serrata. Evolution 56: 1068-1073.

Holm S. 1979. A simple sequentially rejective multiple test procedure. Scand. J. Stat. 6: 65-70.

Imasheva AG, Bubli OA, Lazenby OE, Zhivotovsky LA (1995). Geographic differentiation in wing shape in Drosophila melanogaster. Genetica 96: 303-306.

Klaczko LB, Bitner-Mathé BC (1990). On the edge of a wing. Nature 346: 321.

Klingenberg CP (2002). Morphometrics and the role of the phenotype in studies of the evolution of developmental mechanisms. Gene 287: 3-10.

Lessells CM, Boag PT (1987). Unrepeatable repeatabilities: a common mistake. Auk 104: 116-121.

Patterson JT, Wheeler MR (1942). Description of new species of the subgenera Hirtodrosophila and Drosophila. Univ. Texas Publ. 4213: 67-109.

Pereira MAQR, Vilela CR, Sene FM (1983). Notes on breeding and feeding sites of some species of the repleta group of the genus Drosophila (Diptera, Drosophilidae). Ciên. Cult. 35: 1313-1319.

Pezzoli MC, Guerra D, Giorgi G, Garoia F, Cavicchi S (1997). Developmental constraints and wing shape variation in natural populations of Drosophila melanogaster. Heredity 79: 572-577.

Riska B, Prout T, Turelli M (1989). Laboratory estimates of heritabilities and genetic correlations in nature. Genetics 123: 865-871.

Rohlf FJ (1998). TpsDig version 1.18 www.Life.Bio.SUNYSB. edu.

Rohlf FJ, Archie JW (1984). A comparison of Fourier methods for the description of wing shape in mosquitoes (Dipetera: Culcidae). Syst. Zool. 33: 302-317.

Roff DA, Mousseau TA (1987). Quantitative genetics and fitness: lessons from Drosophila. Heredity 58: 103-118.

Sene FM (1986). Geographic and ecological pattern of chromosome polymorphism in Drosophila mercatorum pararepleta. Rev Bras Biol 9: 573-591.

Shorrocks B (1972). Drosophila. Ginn \& Company Limited: London.

Vilela CR (1983). A Revision of the Drosophila repleta group (Diptera, Drosophilidae). Rev Bras Entomol. 27: 1-114.

Vilela CR, Pereira MAQR, Sene FM (1983). Preliminary data on the geographical distribution of Drosophila species within morphoclimatic domains of Brazil. II. The repleta group. Ciênc. Cult. 35: 66-70.

Weber K, Eisman R, Higgins S, Morey L, Patty A, Tausek M, Zeng ZB (2001). An analysis of polygenes affecting wing shape on chromosome II in Drosophila melanogaster. Genetics 159: 1045-1057.

Weber K, Eisman R, Morey L, Patty A, Sparks J, Tausek M, Zeng ZB (1999). An analysis of polygenes affecting wing shape on chromosome III in Drosophila melanogaster. Genetics 153: 773-786. 